\title{
Glucose transporters in the uterus: an analysis of tissue distribution and proposed physiological roles
}

\author{
Antonina I Frolova and Kelle H Moley \\ Department of Obstetrics and Gynecology, Washington University School of Medicine, St Louis, Missouri 63122, USA \\ Correspondence should be addressed to KH Moley; Email: moleyk@wustl.edu
}

\begin{abstract}
Facilitative glucose transport molecules (glucose transporters, GLUTs) are responsible for glucose transport across cellular membranes. Of the 14 family members, expression of nine has been reported in the murine uterus and seven in the human uterus. Some studies reveal that adequate glucose uptake and metabolism are essential for the proper differentiation of the uterine endometrium toward a receptive state capable of supporting embryo implantation. However, the mechanistic role of GLUTs in endometrial function remains poorly understood. This review aims to present the current knowledge about GLUT expression in the uterus and distribution among the different cell types within the endometrium. In addition, it analyzes the available data in the context of roles GLUTs may play in normal uterine physiology as well as the pathological conditions of infertility, endometrial cancer, and polycystic ovarian syndrome.
\end{abstract}

Reproduction (2011) 142 211-220

\section{Introduction}

The uterine endometrium is a highly active tissue that is made up of several cell types, which include stromal, luminal epithelial, glandular epithelial, and endothelial cells. The endometrial stroma can be functionally distinguished into two layers: a) functionalis, which is the transient layer positioned directly below the luminal epithelium undergoing the cyclical changes associated with the menstrual cycle, and b) basalis, which is the stable layer located below the functionalis and is adjacent to the myometrium that contains the gland fundi. The dynamic changes seen in the epithelial and stromal cells associated with the menstrual cycle and pregnancy, including proliferation, apoptosis, and differentiation, are metabolically demanding (Strauss \& Barbieri 2009). The progressively accumulating data strongly suggest that glucose metabolism is important for the preparation of the epithelium and stroma for embryo implantation during early pregnancy, and especially for the proper differentiation of the functionalis layer into the decidua capable of supporting the developing conceptus (von Wolff et al. 2003, Frolova et al. 2009, Kim \& Moley 2009, Frolova \& Moley 2011).

The first step in glucose utilization is its uptake into the cell, which can be mediated by either the sodiumcoupled glucose transporters (SGLTs, now known as the SLC5 family) or the facilitative glucose transporters (GLUTs, now known as the SLC2 family). The latter are used by most mammalian cell types to transfer various hexose molecules and will be the focus of this review. The human SLC2 protein family contains 14 currently known isoforms and each member has a distinct tissuespecific expression and binding affinities for individual hexose substrates (Augustin 2010). Murine homologs have been identified for most of the GLUTs, except SLC2A11 (GLUT11). SLC2A1-5 (GLUT1-5) were the first members of the family to be described and, thus, have been the most studied, with SLC2A1 and SLC2A4 (GLUT4) being the focus of the majority of publications. During the late 1990s and early 2000s, around the time of the completions of the human genome project, additional putative GLUTs were identified (SLC2A6-14), and there is now a growing amount of work surrounding the possible functions of these new members.

Expression of some of the GLUTs has been detected in the murine and human uteri and a few of them have been characterized in terms of possible functions. Table 1 presents GLUTs that have been identified in the uterus of either the human or the mouse model. It is worth mentioning that expression of a few GLUTs has been ruled out in the uterus. Specifically, multiple groups have reported that SLC2A2 is not expressed in either the murine or the human endometrium (von Wolff et al. 2003, Frolova \& Moley 2011). SLC2A5 expression is also undetectable in the human endometrium. However, very low levels of Slc2a5 mRNA transcript are present in the murine endometrial stroma (von Wolff et al. 2003, Frolova \& Moley 2011). This review primarily focuses on SLC2A1, 3, 4 and 8, which are present in both the 
Table 1 Glucose transporter (GLUT (SLC2 family)) expression in the uterus.

\begin{tabular}{|c|c|c|c|c|}
\hline Transporter & $\begin{array}{l}K_{\mathrm{m}} \text { for } \\
\text { glucose }\end{array}$ & Endometrium & Tissue distribution & References \\
\hline SLC2A1 (GLUT1) & 3 & $\begin{array}{l}\text { Whole uterus }(R, M, H) \\
\text { Stroma }(M, H) \\
\text { Decidua }(M, H) \\
\text { Luminal epithelium }(M, H) \\
\text { Glandular epithelium }(M, H)\end{array}$ & $\begin{array}{l}\text { Ubiquitous } \\
\text { Highest in erythrocytes } \\
\text { and brain }\end{array}$ & $\begin{array}{l}\text { Yamaguchi et al. (1996), Welch \& Gorski (1999), } \\
\text { Korgun et al. (2001), von Wolff et al. (2003), } \\
\text { Frolova et al. (2009), Kim \& Moley (2009) and } \\
\text { Frolova \& Moley (2011) }\end{array}$ \\
\hline SLC2A3 (GLUT3) & 1.5 & $\begin{array}{l}\text { Stroma }(M, H) \\
\text { Decidua }(M, H)\end{array}$ & $\begin{array}{l}\text { Brain, placenta, and } \\
\text { preimplantation embryo }\end{array}$ & $\begin{array}{l}\text { Yamaguchi et al. (1996), Hahn et al. (2001), } \\
\text { von Wolff et al. (2003), Korgun et al. (2005) } \\
\text { and Frolova \& Moley (2011) }\end{array}$ \\
\hline SLC2A4 (GLUT4) & $2-10$ & $\begin{array}{l}\text { Whole uterus }(R, M, H) \\
\text { Stroma }(R, M) \\
\text { Decidua }(R, M) \\
\text { Luminal epithelium }(R, M, H) \\
\text { Glandular epithelium }(R, M)\end{array}$ & $\begin{array}{l}\text { Skeletal muscle, adipose } \\
\text { tissue, and heart }\end{array}$ & $\begin{array}{l}\text { Welch \& Gorski (1999), Korgun et al. (2001), } \\
\text { von Wolff et al. (2003), Mozzanega et al. } \\
\text { (2004), Kohan et al. (2010) and Frolova \& } \\
\text { Moley (2011) }\end{array}$ \\
\hline SLC2A6 (GLUT6) & NA & $\begin{array}{l}\text { Stroma }(M, H) \\
\text { Decidua }(M, H)\end{array}$ & Leukocytes, brain, and spleen & Frolova \& Moley (2011) \\
\hline SLC2A8 (GLUT8) & 2 & $\begin{array}{l}\text { Whole uterus }(\mathrm{M}, \mathrm{H}) \\
\text { Stroma }(\mathrm{M}, \mathrm{H}) \\
\text { Decidua }(\mathrm{M}, \mathrm{H}) \\
\text { Luminal epithelium }(\mathrm{M}) \\
\text { Glandular epithelium }(\mathrm{M})\end{array}$ & $\begin{array}{l}\text { Testis, brain, liver, heart, } \\
\text { skeletal muscle, and } \\
\text { adipose tissue }\end{array}$ & $\begin{array}{l}\text { Flessner \& Moley (2009), Kim \& Moley (2009) } \\
\quad \text { and Frolova \& Moley (2011) }\end{array}$ \\
\hline SLC2A9 (GLUT9) & 0.6 & $\begin{array}{l}\text { Stroma }(M, H) \\
\text { Decidua }(M, H)\end{array}$ & $\begin{array}{l}\text { Kidney, liver, small intestine, } \\
\text { placenta, and lung }\end{array}$ & Kim \& Moley (2009) and Frolova \& Moley (2011) \\
\hline SLC2A10 (GLUT10) & $\begin{array}{l}0.3 \\
(2-\mathrm{DG})\end{array}$ & $\begin{array}{l}\text { Stroma }(M, H) \\
\text { Decidua }(M, H)\end{array}$ & $\begin{array}{l}\text { Heart, lung, brain, liver, } \\
\text { skeletal muscle, placenta, } \\
\text { and kidney }\end{array}$ & Frolova \& Moley (2011) \\
\hline SLC2A12 (GLUT12) & NA & $\begin{array}{l}\text { Stroma }(M, H) \\
\text { Decidua }(M, H)\end{array}$ & $\begin{array}{l}\text { Skeletal muscle, heart, small } \\
\text { intestine, and prostate }\end{array}$ & Frolova \& Moley (2011) \\
\hline
\end{tabular}

$\mathrm{R}$, rat; $\mathrm{M}$, mouse; $\mathrm{H}$, human.

murine and the human uteri and are either the more abundant among the GLUTs in this tissue or have been more extensively characterized in the uterine endometrium. The possible involvement of GLUTs in uterine pathology, such as infertility, polycystic ovary syndrome (PCOS) and endometrial cancer will be discussed.

\section{SLC2 expression in the uterine endometrium}

\section{SLC2A1}

SLC2A1 was the first facilitative GLUT to be discovered in 1985 and continues to be one of the two most studied GLUTs (Mueckler et al. 1985). It has a high affinity for glucose $\left(K_{\mathrm{m}}\right.$ of $\left.\sim 3 \mathrm{mM}\right)$ and for 2-deoxyglucose $\left(K_{\mathrm{m}}\right.$ of $\sim 6.9 \mathrm{mM}$ ) when expressed in Xenopus laevis oocytes (Mueckler 1994, Uldry et al. 2002, Augustin 2010). Due to its ubiquitous expression in all of the organs, it is commonly thought to be responsible for the basal level of glucose uptake in most cell types. However, often the tissue-restricted GLUTs are more abundant and may play bigger roles in tissue-specific glucose homeostasis (Mueckler 1994). Therefore, while reports on SLC2A1 expression within a cell type or tissue are numerous, the relative abundance of SLC2A1 versus other GLUTs or additional mechanistic details is necessary to understand its function.

SLC2A1 was also the first GLUT identified in the endometrium. Slc2a1 mRNA was initially detected in the rat decidua, and its expression was found to increase during gestation, indicating a possible role for SLC2A1 in maintenance of pregnancy and fetal development (Yamaguchi et al. 1996). Another group reported that SLC2A1 protein localizes to the luminal epithelium, the stroma, and the primary decidua in the pregnant rat uterus (Korgun et al. 2001). This study also confirmed that SLC2A1 expression increased in the decidua as pregnancy progressed up to gestational day 8 . Our group recently reported that S/c2a1 mRNA in the mouse endometrial stroma is the most abundant among the GLUTs (Frolova \& Moley 2011). This finding implicates SLC2A1 as the primary GLUT in this tissue and perhaps a major player in early pregnancy progression. Slc2a1 mRNA and protein levels in murine endometrial stroma increased throughout the process of decidualization both in vitro and in vivo, further supporting this hypothesis (Fig. 1A; Frolova et al. 2009).

Estradiol $\left(\mathrm{E}_{2}\right)$ treatment has long been known to affect glucose utilization in the rat uterus (Smith 1967). In 1968, Jack Gorski's group reported that the increase in glucose uptake seen in whole rat uterus on $E_{2}$ administration most likely results from an increase in the synthesis of a transport protein (Smith \& Gorski 1968). Many years later, in 1999, the same group found that expression of SLC2A1 protein in the immature rat uterus increased $4-6 \mathrm{~h}$ after $\mathrm{E}_{2}$ administration (Welch \& Gorski 1999), suggesting that this was the transporter responsible for the $E_{2}$-induced increase in glucose uptake observed in the previous study. In contrast, in 


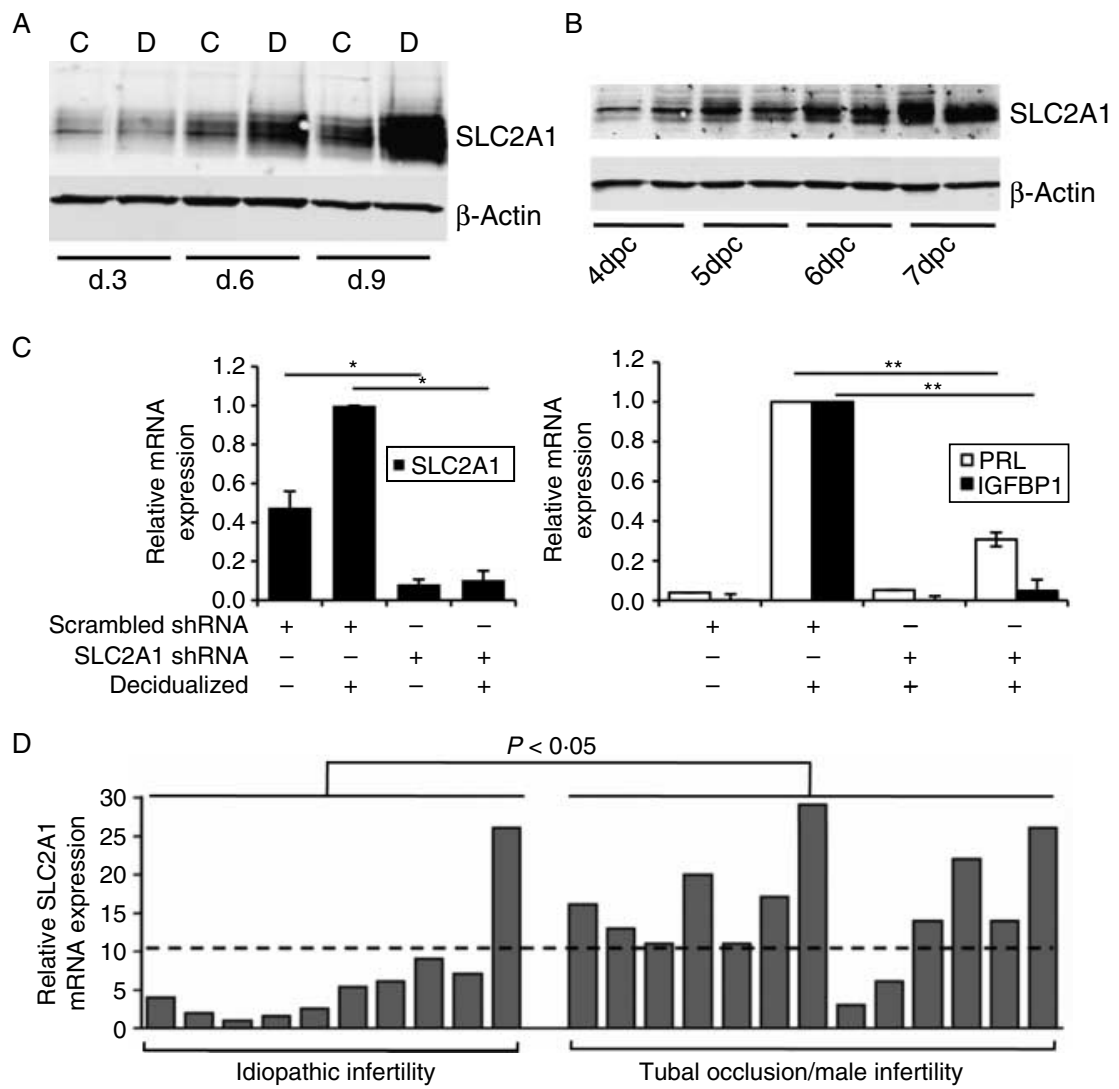

Figure 1 (A) SLC2A1 protein levels in primary human endometrial stromal cells increase during decidualization in vitro. (B) SLC2A1 expression in cells isolated from the decidual tissue of pregnant mice is increased throughout early gestation. Panels $A$ and $B$ are reproduced, with permission, from Frolova A, Flessner L, Chi M, Kim ST, Foyouzi-Yousefi N \& Moley KH 2009 Facilitative glucose transporter type 1 is differentially regulated by progesterone and estrogen in murine and human endometrial stromal cells. Endocrinology $1501512-1520$. (C) 2009 The Endocrine Society. (C) SLC2A1 knockdown with shRNA expressing lentivirus reduces the expression of decidual markers PRL and IGFBP1 in human ESCs decidualized in vitro. ${ }^{*} P<0.005,{ }^{*} P<0.01$ relative to uninfected ESCs treated with MPA and db-cAMP. Reproduced, with permission, from Frolova Al \& Moley KH 2011 Quantitative analysis of glucose transporter mRNAs in endometrial stromal cells reveals critical role of GLUT1 in uterine receptivity. Endocrinology 152 2123-2128. (c) 2011 The Endocrine Society. (D) SLC2A1 levels are decreased in the ESCs isolated from women with idiopathic infertility versus those with infertility caused by known factors that are independent of endometrial function. Reproduced, with permission, from von Wolff M, Ursel S, Hahn U, Steldinger R \& Strowitzki T 2003 Glucose transporter proteins (GLUT) in human endometrium: expression, regulation, and function throughout the menstrual cycle and in early pregnancy. Journal of Clinical Endocrinology and Metabolism $883885-3892$. (C) 2003 The Endocrine Society.

the non-pregnant murine uterus, Slc2a1 expression is highest during estrous, the progesterone $\left(\mathrm{P}_{4}\right)$-dominant stage of the estrous cycle (Frolova et al. 2009, Kim \& Moley 2009). Murine SLC2A1 is predominantly localized to the glandular and luminal epithelia in the nonpregnant endometrium but is also present in the stroma. Moreover, the in vivo experiments using an ovariectomized mouse model also revealed that $\mathrm{P}_{4}$ is responsible for the upregulation of SLC2A1 protein in the epithelial cells of the murine uterus. In addition, a $\mathrm{P}_{4}$-mediated upregulation of SLC2A1 protein and a reversal on $E_{2}$ administration has been observed in isolated murine stromal cells (Fig. 1A; Frolova et al. 2009). The discrepancy among the reports may be due to a number of variables. First, while unlikely, there could be species-specific differences between the mouse and the rat uteri in the hormonal regulation of glucose uptake. Secondly, a much higher dose of $E_{2}$ was used in the immature rat study and could account for an effect not seen with more physiological doses of the hormone, which were used in the murine experiments.

Analyzing the endometrium, and especially its function during embryo implantation and pregnancy, is a more difficult task in the human than in the mouse for obvious ethical issues. However, well-designed studies have already provided insight into SLC2A1 expression and function in the human endometrium. von Wolff et al. (2003) were the first to report presence of SLC2A1 in human endometrial biopsies taken from non-gravid and gravid uteri. In addition, they reported that expression of $S L C 2 A 1 \mathrm{mRNA}$ in the endometrium increased from the proliferative (estrogen-dominated) phase to the secretory $\left(\mathrm{P}_{4}\right.$-mediated) phase and it was further increased in early gestation, when $\mathrm{P}_{4}$ levels continue to dominate. 
Further analysis of the endometrial biopsies revealed that the increased SLC2A1 protein levels were due to enhanced expression specifically in the stromal cells and not the epithelium. In contrast, SLC2A1 levels in the epithelial cells remained high throughout the menstrual cycle and early pregnancy. Other groups have confirmed the presence of SLC2A1 protein in stromal and decidual cells from human biopsies (Fig. 1B; Korgun et al. 2005, Goldman et al. 2006, Frolova et al. 2009). Similar to the findings in mice, human SLC2A1 mRNA was reported to be the most abundant GLUT in primary endometrial stromal cells before and after decidualization in vitro (Frolova \& Moley 2011). On decidualization of primary stromal cells in vitro, SLC2A1 mRNA and protein drastically increase, from twofold on day 3 to approximately tenfold on day 9 of treatment culture (Frolova et al. 2009). Since the human stroma in vivo begins the process of decidualization toward the end of the secretory phase, even in the absence of an embryo, the observed increase in SLC2A1 expression in the human endometrium coincides with this $\mathrm{P}_{4}$-driven decidualization process. These findings parallel reports in the mouse, where SLC2A1 is also upregulated during decidualization, but this process starts later, closer to the time of embryo implantation.

Finally, it is important to remember that GLUT localization in the cell is indicative of the protein's function. Cell fractionation studies determined that SLC2A1 protein is present in both the plasma membrane and the intracellular membrane fractions in murine endometrial stromal cells (Frolova et al. 2009). On $\mathrm{P}_{4}$ treatment, $\mathrm{SLC} 2 \mathrm{~A} 1$ protein in the plasma membrane fraction increased, indicating that the newly expressed SLC2A1 is functional and transporting glucose into the cell. The cell surface localization of SLC2A1 was confirmed by photolabeling with Bio-ATB-BMPA, a compound that binds irreversibly after crosslinking to the exofacial domain of GLUTs. In addition, SLC2A1 was found at the basolateral surface of epithelial cells in mice (Kim \& Moley 2009).

Although the studies regarding S/C2a1 expression in the human, mouse, and rat endometria are still few in number and even contradictory, some interesting preliminary conclusions can already be drawn from them. 1) SLC2A1 protein is present in all three major cell types of the human and rodent endometria. 2) In a non-gravid uterus, SLC2A1 is present in higher concentrations in the epithelial cells when compared with the stromal cells. 3) SLC2A1 expression increases in the stromal compartment during decidualization. 4) SLC2A1 in the murine stromal cells is upregulated by $\mathrm{P}_{4}$ and downregulated by $E_{2}$ and is therefore increased during pregnancy, when $\mathrm{P}_{4}$ dominates. Taken together, these data suggest that SLC2A1 is the main GLUT responsible for glucose uptake into the endometrial stromal cells. Further studies are required to properly characterize SLC2A1 in the epithelial cells, as SLC2A1 is strongly expressed in this cell type as well.

\section{SLC2A3}

SLC2A3 is primarily expressed in tissues with a high demand for glucose, such as the brain, placenta, sperm, preimplantation embryos, and some cancers (Shepherd et al. 1992, Haber et al. 1993, Pantaleon et al. 1997). SLC2A3 is well fitted for tissues that have a high metabolic demand because of its higher affinity for glucose $\left(K_{\mathrm{m}}\right.$ value for 2-deoxyglucose $\left.\sim 1.4 \mathrm{mM}\right)$ compared with SLC2A1, 2, and 4 (see Table 1; Arbuckle et al. 1996, Simpson et al. 2008). In the uterus, SLC2A3 has been studied much less than SLC2A1. However, it has been studied, in the context of stromal cell decidualization and during pregnancy, that existing studies are primarily observational.

S/c2a3 mRNA expression was reported in mouse decidua and found to be detectably decreased during the early progression of pregnancy (Yamaguchi et al. 1996). This downregulation was confirmed in the rat uterus where SLC2A3 protein was reported in the uterine epithelium and stroma starting on gestational day 1 and its expression increased through day 4 (Korgun et al. 2001). In addition, in the latter study, the immunohistochemical staining revealed that SLC2A3 was more abundant in the uterine stroma than the epithelium. In the human, immunohistochemical staining identified SLC2A3 protein in the proliferative endometrium and in the decidua, but no changes in expression were observed throughout different stages of the menstrual cycle or during the beginning of pregnancy (Hahn et al. 2001, von Wolff et al. 2003, Korgun et al. 2005). However, one group reported that human SLC2A3 staining was primarily localized to leukocytes and that this cell population was responsible for the SLC2A3 expression observed in the decidua (von Wolff et al. 2003). Finally, our group has recently reported that Slc2a3 mRNA levels are the second and third highest among the GLUT family members in the endometrial stromal cells isolated from the mouse and human respectively (Frolova \& Moley 2011).

The recent finding that SLC2A3 is expressed in the uterine stroma and decidua is novel and interesting, when analyzed in the context of SLC2A3 expression in trophoblasts (Hahn et al. 2001, Simpson et al. 2008). SLC2A3 is expressed only in the early, first trimester trophoblast cells and not in term placenta, a finding that is consistent between the mouse and the human. This early expression is fitting, as this is a time of decreased glucose substrate surrounding the embryo because the extravillous trophoblast has not fully invaded the uterine stroma to reach the maternal blood supply. Thus, a highaffinity transporter such as SLC2A3 would be beneficial in scavenging existing glucose to supply nutrients to a rapidly growing and developing embryo. While the trophoblast is invading the decidual compartment and establishing its connection with the vascular bed, the decidua is serving as the nutritional support for the 
embryo. Therefore, it is not surprising that it would also express SLC2A3 to more efficiently take up glucose from its surroundings. This hypothesis is supported by the observations that, in the mouse, the decidua is short lived; it starts involution around day $9 \mathrm{pc}$, and retreats as the placenta forms at its interface, replacing it not only functionally but also physically (Glasser et al. 2002). Thus, SLC2A3 is present only in the early stages of trophoblast invasion, in both the decidua and the trophoblast, when the glucose supply is limited, as a permanent and direct connection with the maternal blood supply is not yet established.

\section{SLC2A4}

SLC2A4 is likely the most studied among the membrane transport proteins due to the major role it plays in whole body glucose homeostasis and the pathogenesis of type II diabetes mellitus (Thorens \& Mueckler 2010). SLC2A4 is primarily expressed in the insulin-sensitive skeletal muscle and adipose tissue (James et al. 1988). Insulin, released by the pancreas as a response to high glucose levels, signals SLC2A4 to translocate from an intracellular compartment to the plasma membrane, causing a rapid 10- to 40-fold increase in glucose uptake by these cells (Bryant et al. 2002, Scheepers et al. 2004). While the exact mechanisms responsible for this translocation remain controversial and highly debated in the field, it was clearly shown that defects in insulin-stimulated SLC2A4 translocation in skeletal muscle are responsible for the insulin resistance seen in obesity and type II diabetes (Shepherd \& Kahn 1999). In addition, SLC2A4 expression is altered in adipose tissue in states of obesity and insulin resistance.

Reports regarding SLC2A4 expression in the uterus are limited. SLC2A4 protein and mRNA expression were first observed in whole immature rat uterus, although at concentrations far below than those seen in skeletal muscle (Welch \& Gorski 1999). Another group presented immunohistochemical evidence that SLC2A4 is expressed throughout the uterine epithelium, glands, and stroma in the non-gravid rat uterus and in the decidua through gestational day 8 (Korgun et al. 2001). Both of these reports also determined that while other GLUTs, such as SLC2A1 and 3, were localized primarily at the plasma membrane, SLC2A4 was distributed between the cell surface and the cytoplasm. This localization pattern is consistent with the ability of SLC2A4 to translocate to the plasma membrane from an intercellular compartment and increase glucose uptake in response to appropriate stimuli. Recently, our group presented quantitative data that S/c2a 4 mRNA levels can be found in the murine endometrial stroma, but at levels that are 100- to 1000-fold lower than other, more abundant, GLUTs (Frolova \& Moley 2011).

Data regarding SLC2A4 in the human uterine tissue are even more scarce and highly contradictory. von Wolff et al. (2003) excluded SLC2A4 expression in the human uterus by RNase protection assay and northern blot. Our group's quantitative real-time PCR-based approach also determined SLC2A4 mRNA levels in the human endometrial stromal cells to be below detection levels (Frolova \& Moley 2011). Other reports analyzing human endometrial biopsies cited SLC2A4 mRNA and protein in the endometrium (Mozzanega et al. 2004, Kohan et al. 2010). However, immunohistochemical staining of SLC2A4 was only present in the epithelial cells and not in the stroma (Mozzanega et al. 2004).

Although more research regarding SLC2A4 expression and function in the uterus is needed, the data presented thus far indicate that the levels of this GLUT in the endometrium are very low, sometimes below detection thresholds, which may explain the contradictory reports.

\section{$S L C 2 A B$}

SLC2A8 is a recently discovered member of the SLC2 family and knowledge of its function remains vague. Testes show the highest levels of SLC2A8 expression, but it is also found in a number of other tissues such as liver, spleen, lung, brown adipose, and blastocysts (Carayannopoulos et al. 2000, Ibberson et al. 2000). SLC2A8 is a member of the class III transporters and has a high affinity for glucose $\left(K_{\mathrm{m}} \sim 2 \mathrm{mM}\right)$. However, fructose and galactose can compete with glucose for transport via SLC2A8, leaving its substrate specificity still somewhat ambiguous (Frolova \& Moley 2011). SLC2A8 protein has only recently been identified in the endometrium. Its expression in the murine uterus appears to be highest during estrous in a non-gravid uterus and dramatically increases on embryo implantation and stromal decidualization (Kim \& Moley 2009). Interestingly, unlike SLC2A1, SLC2A8 is localized at both the basolateral and the apical surfaces of the luminal and glandular epithelium. Quantitative studies reveal that levels of SLC2A8 mRNA in the endometrial stromal cells are moderate compared with those of other GLUTs in both the mouse and the human, but the copy number increases on in vitro decidualization (Frolova \& Moley 2011).

The most intriguing aspect of SLC2A8 is its intracellular localization. Other GLUTs are either constitutively located at the cell surface (SLC2A1, 3, and 5) or are shuttled between an intercellular storage compartment and the cell surface in response to a stimulus such as insulin or high glucose (SLC2A4; see Fig. 2; Schmidt et al. 2009). SLC2A8 has an amino-terminal dileucine motif that is responsible for its intracellular localization and, thus far, except in the blastocyst where it was shown to translocate to the cell surface on insulin stimulation (Carayannopoulos et al. 2000), stimuli for its translocation have not been found. In mouse endometrial stromal cells, cellular fractionation confirmed that SLC2A8 protein is not present at the plasma membrane fraction, and is 


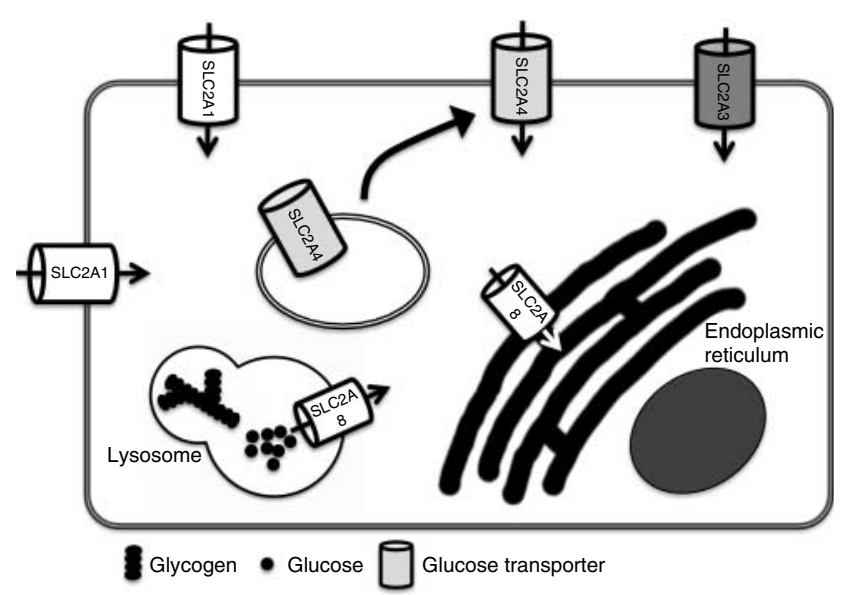

Figure 2 Intracellular localization of GLUTs in endometrial stromal cells.

instead distributed throughout the high- and low-density intercellular membrane fractions (Flessner \& Moley 2009).

Although no reported studies have determined the specific intracellular compartment of SLC2A8 in endometrial stromal cells, its localization has extensively been studied in a number of other cell types. In hippocampal neurons and PC-12 cells, SLC2A8 was detected in the endoplasmic reticulum (Piroli et al. 2002, Widmer et al. 2005, Schmidt et al. 2009). Colocalization studies in $\mathrm{CHO}$ and HEK 293 cells detected stably expressed SLC2A8 in the late endosomes and lysosomes. In addition, immunogold-labeled SLC2A8 was detected in the lysosomes using electron microscopy (Augustin et al. 2005). While further studies are warranted, these observations along with the knowledge that SLC2A8 is localized intracellularly in the stromal cells supports a hypothesis that, in the endometrial stroma, SLC2A8 may be localized to the endoplasmic reticulum (ER), the lysosome, or both organelles (Fig. 2).

The ER-specific SLC2A8 localization could play a role in providing the glucose necessary for glycosylation of proteins during decidualization. During this time, the cells become secretory in nature, providing the developing embryo with nutrients and other factors necessary for development, and since secreted proteins are often glycosylated, it is likely that additional sugars may be required in the ER where this process takes place. In addition, decidual cells have large stores of glycogen, which is classically broken down to glucose-6phosphate in the cytosol and transferred into the ER to be converted to glucose. The resulting glucose is then transferred back out into the cytosol via a, yet unidentified, glucose transport system (Fehr et al. 2005). While there is strong controversy regarding the possible modes of glucose transport out of the ER, evidence exists that facilitative transporters may be responsible and, thus, we hypothesize that in the endometrial stromal cells, SLC2A8 may fulfill this role.

Similarly, SLC2A8 in the lysosomal membrane may play an important role in glycogen degradation. While glycogen is classically degraded in the cytoplasm, some of it is also being continuously degraded in the lysosome and the resulting glucose is once again released into the cytoplasm through a not-fully characterized transport system. It is still unclear why the decidual cells store so much glycogen; however, in the rat, the decidua regresses on the day the embryo begins its fastest growth (Katz \& Abrahamsohn 1987). This growth requires a large quantity of energy, and trophoblast cells are seen directly taking up glycogen from the apoptosing decidua; at the same time, it is feasible that the decidual cells are breaking down the glycogen and releasing glucose into the cytoplasm via SLC2A8 for easier uptake by the trophoblast. In addition, the glycogen could be viewed as an emergency store of energy and the decidual cells must have an efficient system to break it down and release the glucose into the cytoplasm and then out of the cells. Both the ER and the lysosomal breakdown could be accelerated in response to starvation or stress stimuli. In these states, SLC2A8, a high efficiency GLUT, could begin to play a large role in providing the decidual cells with the much-needed additional glucose from the breakdown of glycogen. Finally, the fact that SLC2A8's substrate specificity remains incompletely characterized, it could be responsible for the efflux of other hexoses produced during the lysosomal breakdown of various cellular components.

\section{GLUTs and infertility}

The success of a pregnancy is dependent on proper embryo implantation, an event that is highly coordinated and synchronized between the maternal uterus and the developing blastocyst. The blastocyst, on entering the uterine cavity, must first attach to the epithelium and then invade this layer into the underlying stroma, which is differentiating into the decidua. Metabolic changes are observed in both of these uterine cell types, with the most striking example being the accumulation of glycogen (Demir et al. 2002).

Proper decidualization of endometrial stromal cells in vitro is dependent on adequate glucose concentrations, as cells cultured in glucose concentrations below $2.5 \mathrm{mM}$ exhibit lower levels of decidualization (Frolova \& Moley 2011). Cytochalasin B, an inhibitor of glucose some transporters, but not all, attenuates glucose uptake by endometrial stromal cells, which indicates that the uptake is mediated by a Class I or Class III member of the SLC2 family (von Wolff et al. 2003). Cytochalasin $\mathrm{B}$ also inhibits decidualization of endometrial stromal cells in vitro, which could be attributed to its effects on glucose transport, but could also be the result of a number of other effects this compound has on cell physiology (MacLean-Fletcher \& Pollard 1980).

Levels of SLC2A1 protein, the most abundant GLUT in the endometrial stroma, increase on decidualization both in vitro and in vivo (Fig. 1A and B). Interestingly, 
in vitro shRNA-mediated knockdown of SLC2A1 in endometrial stromal cells downregulates the expression of key decidualization markers (Fig. 1C; Frolova \& Moley 2011). These data indicate that SLC2A1 plays a crucial role in endometrial preparation for embryo implantation and provides additional convincing data that increased glucose uptake is a prerequisite for proper decidualization. Alteration in either maternal serum glucose concentrations, uptake via SLC2A1, or downstream metabolism of glucose could lead to implantation failure and subsequent miscarriage and pregnancy loss. In fact, when SLC2A1 protein levels in endometrial biopsies from women with idiopathic infertility were compared to those with infertility due to either tubal occlusion or male factor causes (non-endometrial infertility), the women with idiopathic infertility had significantly lower levels of SLC2A1 expression (Fig. 1D; von Wolff et al. 2003). Immunohistochemical staining revealed that this decrease was specific to the endometrial stromal cells and not to the luminal or glandular epithelium. Thus, based on the in vitro evidence, idiopathic infertility in some patients could potentially be attributed to decreased glucose uptake by endometrial stromal cells due to lower expression of SLC2A1 and a subsequent decrease in the decidual reaction. In addition, aberrant expression of other GLUTs, such as SLC2A3 and SLC2A8, could play a role in the pathogenesis of infertility as they are both moderately to highly expressed in the endometrial stroma and upregulated during the process of decidualization.

\section{PCOS and GLUTs in the endometrium}

Today, a growing proportion of young women is diagnosed with PCOS, a multifactorial disease, characterized by anovulation, hyperandrogenism, or cystic ovaries. These patients also have increased rates of miscarriage, obesity, and abnormal insulin signaling, including hyperinsulinemia (Sagle et al. 1988, Balen et al. 1993, Dunaif 1997, DeUgarte et al. 2005). Because of this correlation between infertility and the metabolic abnormalities seen in patients with PCOS, a number of groups have proposed that abnormal glucose metabolism in the endometrium could be responsible for the increased miscarriage rates in this population (Fornes et al. 2010, Zhang \& Liao 2010). The observed abnormalities in insulin signaling among women with PCOS have also sparked an interest in SLC2A4 and its possible roles in endometrial preparation for embryo implantation.

As mentioned above, the evidence regarding SLC2A4 expression in the endometrium is highly controversial, and the most recent data suggest that SLC2A4 is present in very low abundance and perhaps even absent in the human uterus. However, several groups have presented evidence that SLC2A4 expression is decreased in endometrial biopsies from women with PCOS versus control (Mozzanega et al. 2004, Fornes et al. 2010,
Kohan et al. 2010). Observations in skeletal muscle cultures suggest that androgens may be responsible for the decreases in SLC2A4 and insulin signaling pathway molecules (Sato et al. 2008). Indeed, Zhang \& Liao (2010) reported that when ex vivo cultures of endometrial glandular epithelium are exposed to testosterone, SLC2A4 protein expression significantly decreases. As increased serum testosterone is a hallmark of PCOS, and the endometrium is a tissue that is highly sensitive to hormones, the decreased SLC2A4 expression observed in endometria from women with PCOS could be directly attributed to the increased levels of testosterone also seen in this population.

Insulin signaling is classically mediated via IRS1 and 2 autophosphorylation, which in turn activates the PI3K pathway and leads to AKT phosphorylation. AKT substrates trigger the translocation of SLC2A4 to the plasma membrane, resulting in glucose uptake. Levels of IRS1 expression and phosphorylation are decreased in the endometria of women with PCOS and hyperinsulinemia compared with controls (Fornes et al. 2010). IRS1 protein and mRNA also decrease in response to testosterone treatment in epithelial cultures in vitro (Zhang \& Liao 2010). This evidence for decreased SLC2A4 expression and IRS1 signaling in the endometrium could be explained by the high levels of serum testosterone and could, in turn, explain the increased infertility rates observed in women with PCOS.

\section{GLUTs in endometrial cancer}

Glucose metabolism has been widely studied in a number of malignant cell types, and it is known that in these cells, metabolism and ATP utilization are increased (Macheda et al. 2005). Cancer cells have increased rates of aerobic glycolysis and expression of glycolytic enzymes. ${ }^{18} \mathrm{~F}$-labeled 2 -fluoro-2-deoxy-D-glucose (FDG) is commonly used to detect tumors on positron emission tomography (PET) scans in the clinic, because the tumor cells accumulate FDG to higher levels than the surrounding tissue, reflecting their higher rate of glucose uptake from the surroundings. The degree of FDG accumulation correlates with higher tumor grade. The increase in glucose uptake, required for the higher rate of glycolysis, is most likely due to increased expression of GLUTs. Indeed enhanced SLC2A1 expression has been shown in a large variety of malignant tumors, including lung (Kurata et al. 1999), liver (Yamamoto et al. 1990), breast (Brown \& Wahl 1993), colorectal (Haber et al. 1998), ovarian and endometrial (Macheda et al. 2005).

Wang et al. (2000) reported that SLC2A1, which could not be detected in benign endometrial epithelium, was detected in atypical hyperplasia and endometrial adenocarcinoma. The fact that SLC2A1 immunohistochemical staining in this study was not detected in benign epithelium while a number of other reports cite SLC2A1 expression in all cell types within 
normal endometrium may, most likely, be attributed to a decreased sensitivity of the antibody used by this group. Therefore, the presence of SLC2A1 in the hyperplasia and adenocarcinoma samples in this study can be interpreted as increased expression of the protein in hyperplasia versus benign tissue. This group proposed that increased SLC2A1 expression in endometrial hyperplasia could be used to predict the development of endometrial carcinoma. In addition, the staining for SLC2A1 was highest in the tumor cells furthest from the benign stroma, which may allow the tumor cells to survive in the increasingly hypoxic environment, a phenomenon that has been described for other cell types in hypoxic conditions (Iliopoulos et al. 1996). Studies have suggested that hypoxia triggers increased Hif1a expression and increased anaerobic metabolism, concurrent with upregulation of SLC2A1 expression (Malhotra et al. 2002). Another report investigated the expression of SLC2A8 in endometrial cancer and found that it is also increased compared with benign proliferative and secretory endometrium (Goldman et al. 2006). SLC2A8 protein expression was upregulated in well-differentiated adenocarcinoma, its expression increased even further in the poorly differentiated endometrial adenocarcinoma, and was highest in the uterine papillary serous carcinomas.

Existing data support a link between the sex hormones, estrogen and $\mathrm{P}_{4}$, and endometrial cancer. Estrogen-only hormone replacement therapy and contraceptives increase the risk for endometrial cancer, but this risk is reversed on addition of $\mathrm{P}_{4}$ to the exogenous hormonal milieu (Henderson \& Feigelson 2000, Persson 2000). SLC2A1 protein expression in the Ishikawa endometrial cancer cell line shows a similar trend, with increased expression on $E_{2}$ treatment and a reversal on addition of $\mathrm{P}_{4}$ (Medina et al. 2004). This study also detected SLC2A2, SLC2A3 and SLC2A4 protein in the Ishikawa cells. SLC2A2 has not been described in the uterine tissue by any other group, but it is not unreasonable that proteins not present in benign uterine endometrium would be induced by the cancer phenotype.

\section{Conclusion}

Recurrent pregnancy loss continues to affect as high as $15 \%$ of couples trying to conceive, and mechanisms responsible for this infertility remain unknown (Allison \& Schust 2009). Glucose is required for the proper development of the early embryo, and it must be adequately transferred from the maternal circulation (Simpson et al. 2008). Prior to full invasion of the trophoblast and establishment of a functioning placenta, the uterine endometrium is primarily responsible for providing the nutritional support for the embryo. Despite this knowledge, very little data regarding the regulatory mechanisms of glucose utilization in the endometrial cells exists, and the importance of this process continues to be neglected. The uterus expresses a disproportionally large number of GLUT family members, but almost no data regarding functional significance of any of these GLUTs in the endometrium are available. Our group has recently investigated the role of SLC2A1 in the process of stromal cell decidualization and found that aberrant expression of this protein may play a role in early pregnancy loss (Frolova \& Moley 2011). However, many more studies are needed in order to determine the role of other GLUTs in the endometrial stroma and epithelium. Some abundant GLUTs in the endometrium, such as SLC2A3, which is also highly expressed in the placenta, and SLC2A8, an intracellular hexose transporter, are interesting candidates for future studies and could provide some mechanisms to idiopathic infertility. A few GLUTs are also hormone regulated at the transcriptional level and this has some implications for their involvement in hormone-responsive cancers, such as those arising in the endometrium. Increased sensitivity to estrogens, which are known to potentiate endometrial cancer, can be a means to upregulate GLUT expression and the higher glucose needs of a metabolically demanding cancer cell. Thus, while a number of developing therapies target the estrogen signaling pathways, the downstream effects on glucose metabolism can also be potential targets in the future.

\section{Declaration of interest}

The authors declare that there is no conflict of interest that could be perceived as prejudicing the impartiality of the review reported.

\section{Funding}

This review was supported by the National Institute of Child Health and Development (R01HD065435) to K H Moley and from the National Institute of Diabetes and Digestive and Kidney Disease (F30DK083224) to A I Frolova.

\section{References}

Allison JL \& Schust DJ 2009 Recurrent first trimester pregnancy loss: revised definitions and novel causes. Current Opinion in Endocrinology, Diabetes, and Obesity 16 446-450. (doi:10.1097/MED.0b013e3283 327fc5)

Arbuckle MI, Kane S, Porter LM, Seatter MJ \& Gould GW 1996 Structurefunction analysis of liver-type (GLUT2) and brain-type (GLUT3) glucose transporters: expression of chimeric transporters in Xenopus oocytes suggests an important role for putative transmembrane helix 7 in determining substrate selectivity. Biochemistry 35 16519-16527. (doi:10.1021/bi962210n)

Augustin R 2010 The protein family of glucose transport facilitators: it's not only about glucose after all. IUBMB Life 62 315-333. (doi:10. 1002/iub.315)

Augustin R, Riley J \& Moley KH 2005 GLUT8 contains a [DE]XXXL[LI] sorting motif and localizes to a late endosomal/lysosomal compartment. Traffic 6 1196-1212. (doi:10.1111/j.1600-0854.2005.00354.x) 
Balen AH, Tan SL, MacDougall J \& Jacobs HS 1993 Miscarriage rates following in vitro fertilization are increased in women with polycystic ovaries and reduced by pituitary desensitization with buserelin. Human Reproduction 8 959-964.

Brown RS \& Wahl RL 1993 Overexpression of Glut-1 glucose transporter in human breast cancer. An immunohistochemical study. Cancer $\mathbf{7 2}$ 2979-2985. (doi:10.1002/1097-0142(19931115)72:10<2979::AIDCNCR2820721020 > 3.0.CO;2-X)

Bryant NJ, Govers R \& James DE 2002 Regulated transport of the glucose transporter GLUT4. Nature Reviews. Molecular Cell Biology 3 267-277. (doi:10.1038/nrm782)

Carayannopoulos MO, Chi MM, Cui Y, Pingsterhaus JM, McKnight RA, Mueckler M, Devaskar SU \& Moley KH 2000 GLUT8 is a glucose transporter responsible for insulin-stimulated glucose uptake in the blastocyst. PNAS 97 7313-7318. (doi:10.1073/pnas.97.13.7313)

Demir R, Kayisli UA, Celik-Ozenci C, Korgun ET, Demir-Weusten AY \& Arici A 2002 Structural differentiation of human uterine luminal and glandular epithelium during early pregnancy: an ultrastructural and immunohistochemical study. Placenta 23 672-684. (doi:10.1053/plac. 2002.0841)

DeUgarte CM, Bartolucci AA \& Azziz R 2005 Prevalence of insulin resistance in the polycystic ovary syndrome using the homeostasis model assessment. Fertility and Sterility 83 1454-1460. (doi:10.1016/j.fertnstert.2004.11.070)

Dunaif A 1997 Insulin resistance and the polycystic ovary syndrome: mechanism and implications for pathogenesis. Endocrine Reviews $\mathbf{1 8}$ 774-800. (doi:10.1210/er.18.6.774)

Fehr M, Takanaga H, Ehrhardt DW \& Frommer WB 2005 Evidence for high-capacity bidirectional glucose transport across the endoplasmic reticulum membrane by genetically encoded fluorescence resonance energy transfer nanosensors. Molecular and Cellular Biology 25 11102-11112. (doi:10.1128/MCB.25.24.11102-11112.2005)

Flessner LB \& Moley KH 2009 Similar [DE]XXXL[LI] motifs differentially target GLUT8 and GLUT12 in Chinese hamster ovary cells. Traffic 10 324-333. (doi:10.1111/j.1600-0854.2008.00866.x)

Fornes R, Ormazabal P, Rosas C, Gabler F, Vantman D, Romero C \& Vega M 2010 Changes in the expression of insulin signaling pathway molecules in endometria from polycystic ovary syndrome women with or without hyperinsulinemia. Molecular Medicine 16 129-136. (doi:10.2119/ molmed.2009.00118)

Frolova AI \& Moley KH 2011 Quantitative analysis of glucose transporter mRNAs in endometrial stromal cells reveals critical role of GLUT1 in uterine receptivity. Endocrinology 152 2123-2128. (doi:10.1210/en. 2010-1266)

Frolova A, Flessner L, Chi M, Kim ST, Foyouzi-Yousefi N \& Moley KH 2009 Facilitative glucose transporter type 1 is differentially regulated by progesterone and estrogen in murine and human endometrial stromal cells. Endocrinology 150 1512-1520. (doi:10.1210/en.2008-1081)

Glasser SR, Aplin J, Giudice LC \& Tabibzadeh S 2002 The Endometrium, pp 675. London: Taylor \& Francis.

Goldman NA, Katz EB, Glenn AS, Weldon RH, Jones JG, Lynch U, Fezzari MJ, Runowicz CD, Goldberg GL \& Charron MJ 2006 GLUT1 and GLUT8 in endometrium and endometrial adenocarcinoma. Modern Pathology 19 1429-1436. (doi:10.1038/modpathol.3800656)

Haber RS, Weinstein SP, O'Boyle E \& Morgello S 1993 Tissue distribution of the human GLUT3 glucose transporter. Endocrinology 132 2538-2543. (doi:10.1210/en.132.6.2538)

Haber RS, Rathan A, Weiser KR, Pritsker A, Itzkowitz SH, Bodian C, Slater G, Weiss A \& Burstein DE 1998 GLUT1 glucose transporter expression in colorectal carcinoma: a marker for poor prognosis. Cancer 83 34-40. (doi:10.1002/(SICl)1097-0142(19980701)83:1 <34::AID-CN CR5 > 3.0.CO;2-E)

Hahn D, Blaschitz A, Korgun ET, Lang I, Desoye G, Skofitsch G \& Dohr G 2001 From maternal glucose to fetal glycogen: expression of key regulators in the human placenta. Molecular Human Reproduction 7 1173-1178. (doi:10.1093/molehr/7.12.1173)

Henderson BE \& Feigelson HS 2000 Hormonal carcinogenesis. Carcinogenesis 21 427-433. (doi:10.1093/carcin/21.3.427)

Ibberson M, Uldry M \& Thorens B 2000 GLUTX1, a novel mammalian glucose transporter expressed in the central nervous system and insulinsensitive tissues. Journal of Biological Chemistry 275 4607-4612. (doi:10.1074/jbc.275.7.4607)
Iliopoulos O, Levy AP, Jiang C, Kaelin WG Jr \& Goldberg MA 1996 Negative regulation of hypoxia-inducible genes by the von HippelLindau protein. PNAS 93 10595-10599. (doi:10.1073/pnas.93.20. 10595)

James DE, Brown R, Navarro J \& Pilch PF 1988 Insulin-regulatable tissues express a unique insulin-sensitive glucose transport protein. Nature 333 183-185. (doi:10.1038/333183a0)

Katz S \& Abrahamsohn PA 1987 Involution of the antimesometrial decidua in the mouse. An ultrastructural study. Anatomica Embryologica 176 251-258. (doi:10.1007/BF00310059)

Kim ST \& Moley KH 2009 Regulation of facilitative glucose transporters and AKT/MAPK/PRKAA signaling via estradiol and progesterone in the mouse uterine epithelium. Biology of Reproduction 81 188-198. (doi:10.1095/ biolreprod.108.072629)

Kohan K, Carvajal R, Gabler F, Vantman D, Romero C \& Vega M 2010 Role of the transcriptional factors FOXO1 and PPARG on gene expression of SLC2A4 in endometrial tissue from women with polycystic ovary syndrome. Reproduction 140 123-131. (doi:10.1530/REP-10-0056)

Korgun ET, Demir R, Hammer A, Dohr G, Desoye G, Skofitsch G \& Hahn T 2001 Glucose transporter expression in rat embryo and uterus during decidualization, implantation, and early postimplantation. Biology of Reproduction 65 1364-1370. (doi:10.1095/biolreprod65.5.1364)

Korgun ET, Celik-Ozenci C, Seval Y, Desoye G \& Demir R 2005 Do glucose transporters have other roles in addition to placental glucose transport during early pregnancy? Histochemistry and Cell Biology 123 621-629. (doi:10.1007/s00418-005-0792-3)

Kurata T, Oguri T, Isobe T, Ishioka S \& Yamakido M 1999 Differential expression of facilitative glucose transporter (GLUT) genes in primary lung cancers and their liver metastases. Japanese Journal of Cancer Research 90 1238-1243.

Macheda ML, Rogers S \& Best JD 2005 Molecular and cellular regulation of glucose transporter (GLUT) proteins in cancer. Journal of Cellular Physiology 202 654-662. (doi:10.1002/jcp.20166)

MacLean-Fletcher S \& Pollard TD 1980 Mechanism of action of cytochalasin B on actin. Cell 20 329-341. (doi:10.1016/0092-8674 (80)90619-4)

Malhotra R, Tyson DG, Sone H, Aoki K, Kumagai AK \& Brosius FC III 2002 Glucose uptake and adenoviral mediated GLUT1 infection decrease hypoxia-induced HIF-1alpha levels in cardiac myocytes. Journal of Molecular and Cellular Cardiology 34 1063-1073. (doi:10.1006/jmcc. 2002.2047)

Medina RA, Meneses AM, Vera JC, Guzman C, Nualart F, Rodriguez F, de los Angeles Garcia M, Kato S, Espinoza N, Monso C et al. 2004 Differential regulation of glucose transporter expression by estrogen and progesterone in Ishikawa endometrial cancer cells. Journal of Endocrinology 182 467-478. (doi:10.1677/joe.0.1820467)

Mozzanega B, Mioni R, Granzotto M, Chiarelli S, Xamin N, Zuliani L, Sicolo N, Marchesoni D \& Vettor R 2004 Obesity reduces the expression of GLUT4 in the endometrium of normoinsulinemic women affected by the polycystic ovary syndrome. Annals of the New York Academy of Sciences 1034 364-374. (doi:10.1196/annals.1335.038)

Mueckler M 1994 Facilitative glucose transporters. European Journal of Biochemistry 219 713-725. (doi:10.1111/j.1432-1033.1994.tb18550.x)

Mueckler M, Caruso C, Baldwin SA, Panico M, Blench I, Morris HR, Allard WJ, Lienhard GE \& Lodish HF 1985 Sequence and structure of a human glucose transporter. Science 229 941-945. (doi:10.1126/science. 3839598)

Pantaleon M, Harvey MB, Pascoe WS, James DE \& Kaye PL 1997 Glucose transporter GLUT3: ontogeny, targeting, and role in the mouse blastocyst. PNAS 94 3795-3800. (doi:10.1073/pnas.94.8.3795)

Persson I 2000 Estrogens in the causation of breast, endometrial and ovarian cancers - evidence and hypotheses from epidemiological findings. Journal of Steroid Biochemistry and Molecular Biology 74 357-364. (doi:10.1016/S0960-0760(00)00113-8)

Piroli GG, Grillo CA, Hoskin EK, Znamensky V, Katz EB, Milner TA, McEwen BS, Charron MJ \& Reagan LP 2002 Peripheral glucose administration stimulates the translocation of GLUT8 glucose transporter to the endoplasmic reticulum in the rat hippocampus. Journal of Comparative Neurology 452 103-114. (doi:10.1002/cne.10368)

Sagle M, Bishop K, Ridley N, Alexander FM, Michel M, Bonney RC, Beard RW \& Franks S 1988 Recurrent early miscarriage and polycystic ovaries. BMJ 297 1027-1028. (doi:10.1136/bmj.297.6655.1027) 
Sato K, Iemitsu M, Aizawa K \& Ajisaka R 2008 Testosterone and DHEA activate the glucose metabolism-related signaling pathway in skeletal muscle. American Journal of Physiology. Endocrinology and Metabolism 294 E961-E968. (doi:10.1152/ajpendo.00678.2007)

Scheepers A, Joost HG \& Schurmann A 2004 The glucose transporter families SGLT and GLUT: molecular basis of normal and aberrant function. Journal of Parenteral and Enteral Nutrition 28 364-371. (doi:10. 1177/0148607104028005364)

Schmidt S, Joost HG \& Schurmann A 2009 GLUT8, the enigmatic intracellular hexose transporter. American Journal of Physiology. Endocrinology and Metabolism 296 E614-E618. (doi:10.1152/ajpendo. 91019.2008)

Shepherd PR \& Kahn BB 1999 Glucose transporters and insulin action implications for insulin resistance and diabetes mellitus. New England Journal of Medicine 341 248-257. (doi:10.1056/NEJM199907223410406)

Shepherd PR, Gould GW, Colville CA, McCoid SC, Gibbs EM \& Kahn BB 1992 Distribution of GLUT3 glucose transporter protein in human tissues. Biochemical and Biophysical Research Communications 188 149-154. (doi:10.1016/0006-291X(92)92362-2)

Simpson IA, Dwyer D, Malide D, Moley KH, Travis A \& Vannucci SJ 2008 The facilitative glucose transporter GLUT3: 20 years of distinction. American Journal of Physiology. Endocrinology and Metabolism 295 E242-E253. (doi:10.1152/ajpendo.90388.2008)

Smith DE 1967 Location of the estrogen effect on uterine glucose metabolism. Proceedings of the Society for Experimental Biology and Medicine 124 746-749.

Smith DE \& Gorski J 1968 Estrogen control of uterine glucose metabolism. An analysis based on the transport and phosphorylation of 2-deoxyglucose. Journal of Biological Chemistry 243 4169-4174.

Strauss JF \& Barbieri RL 2009 Yen and Jaffe's Reproductive Endocrinology: Physiology, Pathophysiology, and Clinical Management, 6 edn. Philadelphia: Saunders Elsevier.

Thorens B \& Mueckler M 2010 Glucose transporters in the 21st century. American Journal of Physiology. Endocrinology and Metabolism 298 E141-E145. (doi:10.1152/ajpendo.00712.2009)
Uldry M, Ibberson M, Hosokawa M \& Thorens B 2002 GLUT2 is a high affinity glucosamine transporter. FEBS Letters 524 199-203. (doi:10. 1016/S0014-5793(02)03058-2)

Wang BY, Kalir T, Sabo E, Sherman DE, Cohen C \& Burstein DE 2000 Immunohistochemical staining of GLUT1 in benign, hyperplastic, and malignant endometrial epithelia. Cancer 88 2774-2781. (doi:10.1002/ 1097-0142(20000615)88:12<2774::AID-CNCR16>3.0.CO;2-I)

Welch RD \& Gorski J 1999 Regulation of glucose transporters by estradiol in the immature rat uterus. Endocrinology 140 3602-3608. (doi:10.1210/ en.140.8.3602)

Widmer M, Uldry M \& Thorens B 2005 GLUT8 subcellular localization and absence of translocation to the plasma membrane in PC12 cells and hippocampal neurons. Endocrinology 146 4727-4736. (doi:10.1210/en. 2005-0668)

von Wolff M, Ursel S, Hahn U, Steldinger R \& Strowitzki T 2003 Glucose transporter proteins (GLUT) in human endometrium: expression, regulation, and function throughout the menstrual cycle and in early pregnancy. Journal of Clinical Endocrinology and Metabolism 88 3885-3892. (doi:10.1210/jc.2002-021890)

Yamaguchi M, Sakata M, Ogura K \& Miyake A 1996 Gestational changes of glucose transporter gene expression in the mouse placenta and decidua. Journal of Endocrinological Investigation 19 567-569.

Yamamoto T, Seino Y, Fukumoto H, Koh G, Yano H, Inagaki N, Yamada Y, Inoue K, Manabe T \& Imura H 1990 Over-expression of facilitative glucose transporter genes in human cancer. Biochemical and Biophysical Research Communications 170 223-230. (doi:10.1016/ 0006-291X(90)91263-R)

Zhang L \& Liao Q 2010 Effects of testosterone and metformin on glucose metabolism in endometrium. Fertility and Sterility 93 2295-2298. (doi:10.1016/j.fertnstert.2009.01.096)

Received 12 April 2011

First decision 3 June 2011

Accepted 3 June 2011 